\title{
Thermal Implications of Phase Transformations during Induration of Iron Ore Pellets Produced from Hematite
}

\author{
Andrew Robert FIRTH and James Robert MANUEL \\ CSIRO Minerals, PO Box 883, Kenmore, Queensland 4069, Australia.
}

(Received on April 7, 2005; accepted on July 6, 2005)

\begin{abstract}
Although extensive development has occurred in recent years for models of induration of iron ore pellets, none of these models have taken into account the partial melting of some of the raw materials. To determine the importance of partial melting and melt phase formation to the energy balance for induration, estimates have been made of the thermodynamic properties of silicoferrite of calcium, SFC, using published techniques. SFC was used in this paper as an example of the initial melt forming minerals in the pellets. Owing to the complexity of the structure of SFC, there was some doubt as to the accuracy of these estimates as they suggested that SFC was not a thermodynamically stable phase, though it exists between 1050 and $1250^{\circ} \mathrm{C}$. As no experimental data was available, however, these 'best available' estimates have been incorporated into a mathematical model to determine the effect of melt phase formation on the induration process. It was found that while there was little effect on the pellet temperature profiles, the overall amount of energy required to indurate the pellets increased by about $1-1.5 \%$ when melt phase formation was included. This suggests that experimental determination of the thermodynamic properties of SFC and other phases produced from the melt would be of benefit in modelling the energy requirements for induration of pellets more accurately.
\end{abstract}

KEY WORDS: iron ore pelletising; pellet induration; complex calcium ferrites; thermodynamic property; estimation of complex oxides; phase equilibria; mathematical modelling; melt formation.

\section{Introduction}

Iron ore pellets have been produced from finely ground iron ore concentrates for over 60 years as an agglomerated feed material for blast furnaces and more recently for direct reduction furnaces. To produce pellets, iron ore concentrate (either hematite $-\mathrm{Fe}_{2} \mathrm{O}_{3}$, or magnetite $-\mathrm{Fe}_{3} \mathrm{O}_{4}$ ) ground to a p80 of $30-70 \mu \mathrm{m}$, along with additives such as limestone, dolomite and a binder, usually bentonite, is added with water to balling discs or drums to produce green balls of 9-16 mm diameter. These green balls are then loaded onto a travelling grate in a packed bed where they are dried and preheated. In "straight-grate" plants, firing (at around $1300-1350^{\circ} \mathrm{C}$ ) and cooling are also completed on the grate, whereas in "grate-kiln" plants the firing process is performed in a rotary kiln before the pellets are transferred into an annular travelling grate cooler. This induration (heat hardening) process produces agglomerates of sufficient size to allow the blast furnace burden to be permeable to reduction gases and strong enough to be shipped around the world.

Over the last 30 years, development of pellet induration has been aided by computer simulation of the process. With the advancement of computer technology in the 1970s and 1980s a number of models of pellet induration were developed. Initially, the development of induration models was confined to the Lurgi straight-grate process ${ }^{1-3)}$ and the shaft furnace, ${ }^{4)}$ but were expanded later to include the complete
Allis-Chambers grate-kiln process. ${ }^{5)}$ Thurlby $^{6-8)}$ expanded the model of the Allis-Chambers grate-kiln process to include gas flow resistances and characteristics of process fans and control systems. More recent advances in modelling of straight-grate pellet induration have been made by COREM, ${ }^{9)}$ which include prediction of pellet metallurgical properties from green ball composition and thermal history. It is probable that there are other advanced pellet induration models in use that have not been published in the open literature for reasons of commercial confidentiality. An excellent review of the necessary equations for modelling iron ore pellet induration (and iron ore sintering) was prepared by Wynnyckyj and Batterham. ${ }^{10)}$

In these published models, there has been little discussion on the formation of a melt phase and product phases from the melt. Examples of these product phases include calcium ferrites with some silica substitution, SFCA (silico-ferrite of calcium and aluminium) ${ }^{11)}$ in systems with over $1 \%$ alumina, magnesioferrite $\left(\mathrm{Mg}_{x} \mathrm{Fe}_{1-x}^{2+} \mathrm{Fe}_{2}^{3+} \mathrm{O}_{4}-x \approx\right.$ 0.3 ) in systems fluxed with dolomite or olivine, and iron substituted calcium silicate glasses (sometimes referred to as "slag"). Iron ore sintering models ${ }^{12,13)}$ assume some calcium ferrite formation and melting, but this treatment is limited to simple calcium ferrites. More complex phases found in industrial pellets have different thermodynamic properties (e.g. enthalpy of formation, standard entropy, enthalpy and entropy of fusion, heat capacity, etc.) to that of hematite, the predominant phase in iron ore pellets, or even 
to that of simple calcium ferrites. Obtaining values for these properties has proven difficult, however, due to the high temperatures involved and the recent nature of their characterisation. In this paper, published thermodynamic estimation techniques have been used to determine the key thermal properties of SFC (silico-ferrite of calcium), an intermediate phase formed during the induration of both iron ore pellets and sinter, in an effort to justify which properties of these melt phases should be measured to improve the energy balance prediction of induration models. The estimated thermal properties have then been trialled in a simple pellet induration model to observe the effect. To gauge the quality of the estimation techniques, some comparisons have been performed with published thermodynamic data for the simple calcium ferrites $\mathrm{CaFe}_{2} \mathrm{O}_{4}$ and $\mathrm{Ca}_{2} \mathrm{Fe}_{2} \mathrm{O}_{5}$.

\section{Formation of SFC in Pellet Induration}

Silico-ferrite of calcium (SFC) is a complex calcium ferrite that forms the basis for the melt phase in both sintering and pelletising. It belongs to the aenigmatite group of minerals and in air has the approximate composition of $\mathrm{Ca}_{2.64} \mathrm{Fe}_{10.52} \mathrm{Si}_{0.74} \mathrm{O}_{20}$, although it can contain some magnesium, replacing calcium. ${ }^{14)} \mathrm{SFC}$ is stable in air between $1050^{\circ} \mathrm{C}$ and $\left.1250^{\circ} \mathrm{C},{ }^{15}\right)$ but alumina can stabilise the structure at higher temperatures causing silico-ferrite of calcium and aluminium (SFCA - typical composition ${ }^{16)}$ $\left.\mathrm{Ca}_{2.45} \mathrm{Fe}_{9.04}^{3+} \mathrm{Al}_{1.74} \mathrm{Fe}_{0.16}^{2+} \mathrm{Si}_{0.6} \mathrm{O}_{20}\right)$ to precipitate from the melt. The formation of SFC follows a complicated path, and there is much conjecture in the literature as to the exact process, ${ }^{17,18)}$ although it is generally agreed that SFC only be formed from hematite (or magnetite oxidised to hematite) in an oxidising atmosphere. The most likely path in pellets is that of initial solid state reactions of lime and silica at contact points to form an olivine phase, and of lime with the hematite to form simple calcium ferrites $\left(\mathrm{CaFe}_{2} \mathrm{O}_{4}\right.$ and $\left.\mathrm{Ca}_{2} \mathrm{Fe}_{2} \mathrm{O}_{5}\right) .{ }^{19)}$ These phases then begin to react with each other to form small amounts of SFC at around $1000^{\circ} \mathrm{C}$. Around $1200^{\circ} \mathrm{C}$, the remaining calcium silicates and simple calcium ferrites begin to melt, accelerating SFC formation. As the pellet temperature increases with firing, the melting of the SFC at around $1250^{\circ} \mathrm{C}$ then accelerates melt formation as silica, hematite and lime are dissolved from the surrounding particles. In dolomite fluxed pellets, the melt phase also allows the transport of magnesium to hematite particles to form magnesioferrite. In areas of the melt where alumina is rich, SFCA is stable at temperatures around $1300^{\circ} \mathrm{C}$ and will precipitate out as the solid phase. Otherwise, the remainder of the melt solidifies as a ferrous calcium silicate glass (slag), the excess iron oxide migrating to nearby hematite particles.

The primary bonding mechanism in pellets is diffusional bonding between hematite particles, caused by grain growth and surface area reduction at high temperature. The presence of some melt phase aids the diffusional bonding as it facilitates the migration of ions. Only in sintering of magnetite concentrates at high temperature does significant diffusional bonding occur. ${ }^{20)}$ Induration of pellets is characterised by a gas atmosphere that is generally oxidising $\left(p_{\mathrm{O}_{2}}>0.18 \mathrm{~atm}\right)$ to minimise magnetite formation, magnetite being stabilised by lower oxygen partial pressures. This has a major influence on the phases formed due to the reduced phase stability field for SFC at higher oxygen partial pressures. ${ }^{14)}$ Lower oxygen partial pressures, such as those generated by overdosing the pellets with coke breeze, ${ }^{21)}$ can also lead to the formation of other phases such as SFCAI. ${ }^{16)}$ SFCA-I (often called platy SFCA) is an analogue of SFCA with a higher $\mathrm{Fe}^{2+}$ content.

\section{Thermodynamic Property Estimation for SFC}

No thermodynamic information, experimentally determined or estimated from theory, is available in the literature for complex calcium ferrites like SFC. This is mainly due to their uncertain chemical formula and their relatively recent characterisation. The aim of this paper is to determine how important such information is likely to be. For this paper, the approximate composition for SFC reported in Pownceby and Patrick ${ }^{15)}$ will be used for calculating thermodynamic properties and the melting point for SFC will be assumed to be $1250^{\circ} \mathrm{C}$. $^{15)}$ The methods evaluated for use can be found in Kubaschewski and Alcock, ${ }^{22)}$ Kubaschewski et al. $^{23)}$ and Moiseev and Sestak. ${ }^{24)}$ As a guide to the accuracy of the methods, estimates of thermodynamic properties for $\mathrm{CaFe}_{2} \mathrm{O}_{4}$ have been compared with published experimental data.

\subsection{Estimation of Standard Enthalpy of Formation}

A method was developed by Aronson ${ }^{25}$ ) for determining the heat of formation of refractory mixed oxides, based on and adding to the Pauling electronegativities of various ions. Aronson ${ }^{25)}$ gave the standard heat of formation calculated by his method for $\mathrm{CaFe}_{2} \mathrm{O}_{4}$ as $-1468 \mathrm{~kJ} / \mathrm{mol}$ and for $\mathrm{Ca}_{2} \mathrm{Fe}_{2} \mathrm{O}_{5}$ as $-2200 \mathrm{~kJ} / \mathrm{mol}$. These values compare favourably to literature experimental values of $-1520 \mathrm{~kJ} /$ $\mathrm{mol}$ and $-2138 \mathrm{~kJ} / \mathrm{mol}$ respectively. These correlate to heats of formation at $25^{\circ} \mathrm{C}$ from the fundamental oxides of $-62 \mathrm{~kJ} / \mathrm{mol}$ for $\mathrm{CaFe}_{2} \mathrm{O}_{4}$ and $-55 \mathrm{~kJ} / \mathrm{mol}$ for $\mathrm{Ca}_{2} \mathrm{Fe}_{2} \mathrm{O}_{5}$.

Using the Aronson method, ${ }^{25)}$ the heat of formation for SFC was determined to be $-6386 \mathrm{~kJ} / \mathrm{mol}$ or alternatively, the heat of reaction for the formation of SFC from its component binary oxides was $+299 \mathrm{~kJ} / \mathrm{mol} \mathrm{SFC}$. The value estimated for SFC for the standard heat of formation from the individual oxides was significantly different to that for the calcium ferrites. This is probably due to the structure of SFC being quite different to that of the simple calcium ferrites, although it is also possible that the Aronson method may not be appropriate for complex structures such as that of SFC.

\subsection{Heat Capacity and Heat of Reaction}

The most appropriate method found to estimate heat capacity was to determine the heat capacity at $25^{\circ} \mathrm{C}$ from Kubaschewski and Ünal's method, ${ }^{26)}$ then model the heat capacity at other temperatures using the three term relationship developed by Kelley. ${ }^{27)}$ The method employed by Kubaschewski and Ünal ${ }^{26}$ was developed from statistical analysis of a large number of inorganic compounds and consisted of summing the cationic and anionic contributions to heat capacity and estimating the melting point $\left(1250^{\circ} \mathrm{C}\right)$. Using this method gave the following expression (Eq. (1)) for heat capacity in terms of temperature ( $T$ in $\mathrm{K})$ : 


$$
C_{\mathrm{p}}=824.7+0.1397 T-1.423 \times 10^{7} T^{-2}\left(\frac{\mathrm{J}}{\mathrm{molK}}\right) \ldots
$$

The Kelley method of modelling heat capacities was also trialled on monocalcium ferrite $\left(\mathrm{CaFe}_{2} \mathrm{O}_{4}\right)$. This gave numbers that were much closer to those determined experimentally by calorimetric methods. ${ }^{28-30)}$ The comparison can be seen in Fig. 1. The Kelley method of approximation still overestimates the heat capacity of $\mathrm{CaFe}_{2} \mathrm{O}_{4}$ by around $8 \%$ from 500-1200 K compared to the experimental values of Bonnickson $^{28)}$ and the values listed in Robie et al. ${ }^{29)}$ It underestimates the values listed in Barin, ${ }^{30)}$ however, by approximately the same amount. The lack of accuracy in estimating the heat capacity for monocalcium ferrite suggests that using the estimation methods Kubaschewski and Unal, ${ }^{26)}$ and Kelley, ${ }^{27)}$ would at best give only a reasonable approximation for SFC. A review of the literature, however, did not discover a more appropriate estimation technique for complex mixed oxides.

The heat capacity of SFC in the liquid phase was assumed to be constant at a value of $1109.6 \mathrm{~J} / \mathrm{mol} \mathrm{K}$. This was given from the approximation of $32.6 \mathrm{~J} / \mathrm{K}$ mol-atom, estimated from the range given in Kubaschewski and Alcock ${ }^{22)}$ and the experimental values for calcium ferrites in Bonnickson. ${ }^{28)}$ It is acknowledged that there may be some error in this assumption, so it should be taken as a first approximation.

The heat of reaction for the formation of SFC from its component oxides as a function of temperature can be seen in Fig. 2. It was derived using the estimate for standard heat of formation derived above combined with the numerical integration of the heat capacity using the following expression (Eq. (2)).

$$
H(T)=H_{298}+\int_{298}^{T} C_{\mathrm{p}} d T
$$

\subsection{Free Energy of Reaction}

The free energy of the reaction to form SFC was obtained by the integration of the heat capacity equation to derive the variation in enthalpy and entropy with temperature, along with the standard enthalpy and entropies of re- action according to Eq. (3).

$$
\Delta G_{r x n}(T)=\Delta H_{r x n}(T)-T \Delta S_{r x n}(T)
$$

The heat of reaction as a function of temperature can be calculated using the heat of reaction at $25^{\circ} \mathrm{C}$ (determined from standard heats of formation) and integration of the heat capacity between $25^{\circ} \mathrm{C}$ and the temperature, T. The entropy of reaction can be determined by a similar method, with the standard entropy of formation for SFC $(577.5 \mathrm{~J} / \mathrm{mol} \mathrm{K})$ being estimated according to Latimer $\left.^{31}\right)$ from ionic contributions. The variation of entropy with temperature is calculated according to Eq. (4), assuming there are no solid-state phase transformations between $25^{\circ} \mathrm{C}$ and the temperature, $T$.

$$
S(T)=S_{298}+\int_{298}^{T} \frac{C_{\mathrm{p}}}{T} d T
$$

From this, the free energy of reaction for SFC formation was calculated as a function of temperature. The results can be seen in Fig. 2.

The estimated results suggested that SFC should not form from its fundamental oxides due to the positive value for the free energy of formation from the component ox-

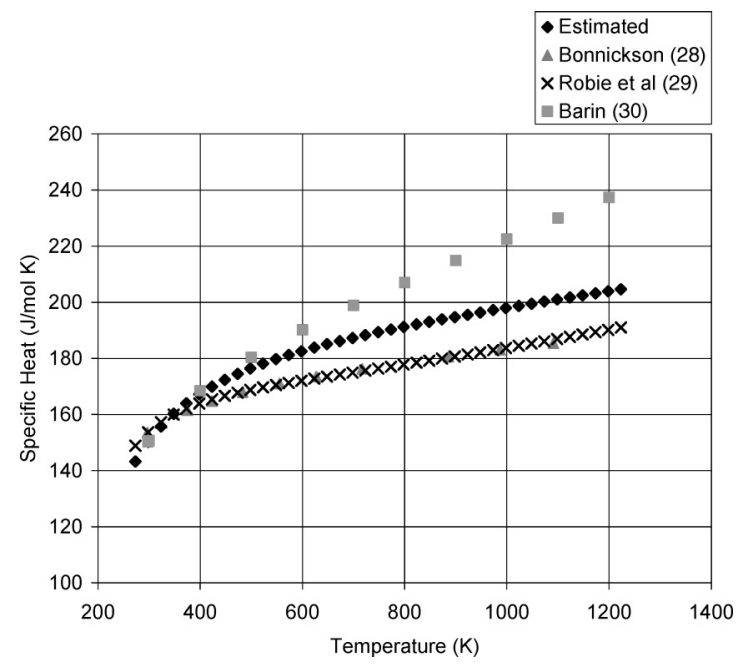

Fig. 1. Comparison of literature values for the specific heat of calcium ferrite $\left(\mathrm{CaFe}_{2} \mathrm{O}_{4}\right)$ to the estimation method of Kubaschewski and Unal, ${ }^{27}$ and Kelley. ${ }^{28}$

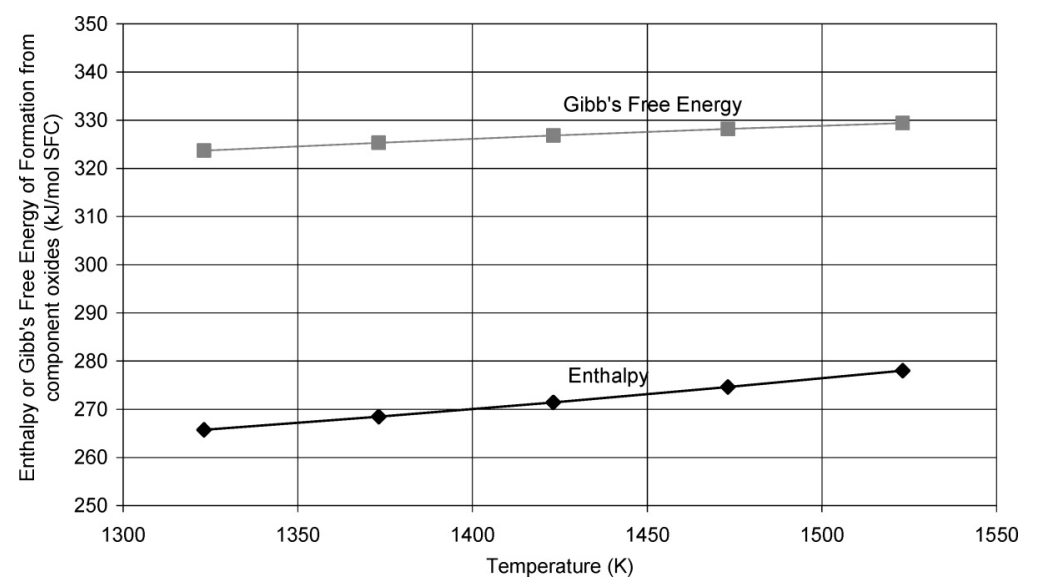

Fig. 2. Variation in estimated enthalpy and Gibbs free energy of reaction for the formation of SFC from its component oxides. 


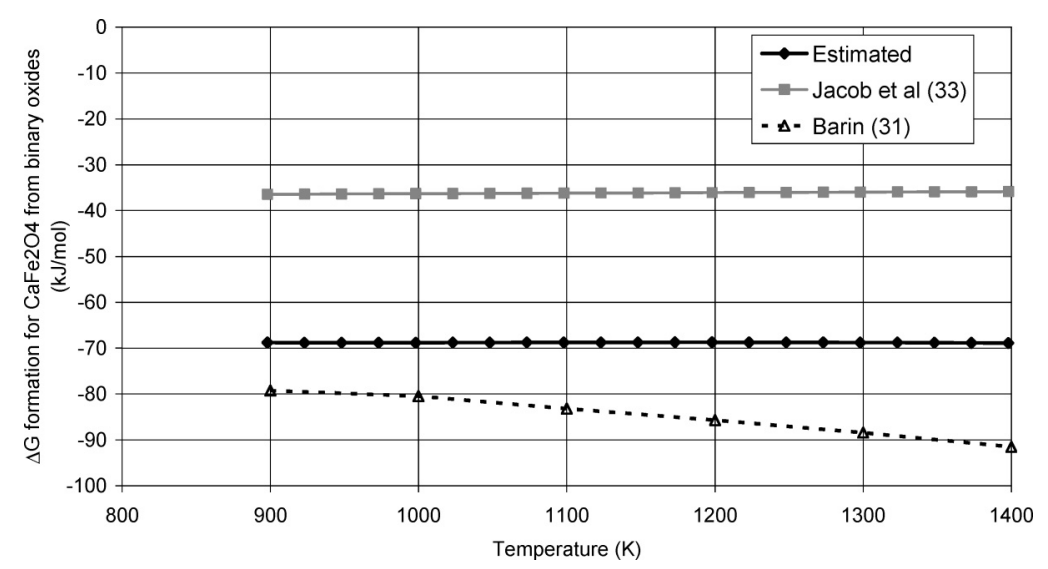

Fig. 3. Difference between estimated and literature values for the Gibbs free energy of formation for calcium ferrite $\left(\mathrm{CaFe}_{2} \mathrm{O}_{4}\right)$.

ides. It should be remembered, however, that the relationship presented was only an estimate. The estimate for the free energy of the SFC product was also checked against the published (Pownceby and Patrick) formation reaction for SFC from hematite, monocalcium ferrite and dicalcium silicate (olivine phase) at $1050^{\circ} \mathrm{C}$. The data used for the reactant mineral phases was obtained from Barin. ${ }^{30)}$ The calculated free energy of the reactants was $-8498.6 \mathrm{~kJ} / \mathrm{mol}$, while the free energy calculated for the product was $-7848.0 \mathrm{~kJ} / \mathrm{mol}$ at $1050^{\circ} \mathrm{C}$, resulting in a free energy change for the reaction of $+650.6 \mathrm{~kJ} / \mathrm{mol}$. This result suggests that the thermodynamic modelling techniques used underestimated the stability of the SFC phase as it has been shown to form experimentally at $1050^{\circ} \mathrm{C} .^{15)}$

The free energies of formation of the simple calcium ferrites $\mathrm{CaFe}_{2} \mathrm{O}_{4}$ and $\mathrm{Ca}_{2} \mathrm{Fe}_{2} \mathrm{O}_{5}$ and other thermodynamic data have been determined experimentally as a function of temperature using electrolytic methods by Jacob et al. ${ }^{32)}$ and Forsberg. ${ }^{33)}$ Their results, however, differ from other studies which used calorimetric methods. ${ }^{28-30)}$ Figure 3 shows the difference between the estimated free energy of formation of $\mathrm{CaFe}_{2} \mathrm{O}_{4}$ and experimental values determined by Jacob et $a l .{ }^{32)}$ and reported in Barin. ${ }^{30)}$ There was a significant difference between the values. A possible reason for the large discrepancy is the effect of ordering in the complex oxide structure on entropy. Kubaschewski and Alcock ${ }^{22}$ discussed the fact that ordering in structures can have a significant impact on the standard entropy of formation. This impact would be even more difficult to estimate for complex structures like that of SFC and can really only be determined by experimental methods.

\subsection{Heat and Entropy of Fusion}

The entropy of fusion for SFC was estimated from the combination of entropies of fusion of the fundamental oxides. There is no other reliable means of estimation except comparing with similar compounds. It is difficult to find any data for similar compounds, however, owing to the complex structure of SFC, which is significantly different even to simple calcium ferrites. Kubaschewski and Alcock $^{22)}$ suggested that the maximum expected error for entropy of fusion using the method of comparison was $15 \%$. The heat of fusion was then estimated using the thermodynamic relationship between the enthalpy and entropy of fusion and the melting point in $\mathrm{K}, 1523 \mathrm{~K}$ (Eq. (5)).

$$
\Delta S_{\text {fus }}=\frac{\Delta H_{\text {fus }}}{T_{\text {fus }}}
$$

Using the above method, the entropy of fusion calculated for SFC was $378 \mathrm{~J} / \mathrm{mol} \mathrm{K}$ and the heat of fusion was calculated to be $576 \mathrm{~kJ} / \mathrm{mol}$. Using the same method, the entropy of fusion for $\mathrm{CaFe}_{2} \mathrm{O}_{4}$ was calculated to be $82.8 \mathrm{~J} / \mathrm{mol} \mathrm{K}$, which compares fairly well with the experimentally determined value of $71.54 \mathrm{~J} / \mathrm{mol} \mathrm{K}$, though the margin of error was near the limit of that suggested by Kubaschewski and Alcock. 22)

\section{Reaction Model: Estimation of Kinetics}

To simplify matters, the formation of the initial calcium ferrites and calcium silicates, further reactions to form SFC, and then the formation of the melt were considered to be one reversible reaction for the purposes of this study. The heat of reaction to form SFC from the component oxides was combined with the heat of fusion of SFC to give the total heat of reaction for formation. Upon solidification, however, only the latent heat component was released, not the heat of reaction from the initial oxides. The resulting equation for such a melting reaction can be seen in Eq. (6).

$$
\frac{d x_{\text {melt }}}{d t}=k_{\text {melt }}\left(\left(x_{\text {melt max }}-x_{\text {melt }}\right)-\frac{x_{\text {melt }}}{K_{\text {eq }}}\right)
$$

The reaction rate constant was calculated from Arrhenius coefficients chosen to match the reaction and melting behaviour of compacts produced in CSIRO laboratories. ${ }^{20)}$ The activation energy was estimated to be $3 \times 10^{5} \mathrm{~J} / \mathrm{mol}$ and the frequency factor was chosen to be $1 \times 10^{8} \mathrm{~s}^{-1}$. The reaction equilibrium constant was taken from the solid and liquid free energies for SFC, with the entropy of the liquid phase adjusted such that the free energy difference between the solid and liquid phases was zero at the melting point of $1250^{\circ} \mathrm{C}$. This was considered to be appropriate as the initial melt is formed from SFC and similar solid phases. For this model, a maximum extent of melting (15\%) was assumed as this would be the approximate proportion of the material that would react to form the SFC melt based on the observations of the microstructure of fluxed pellets with 


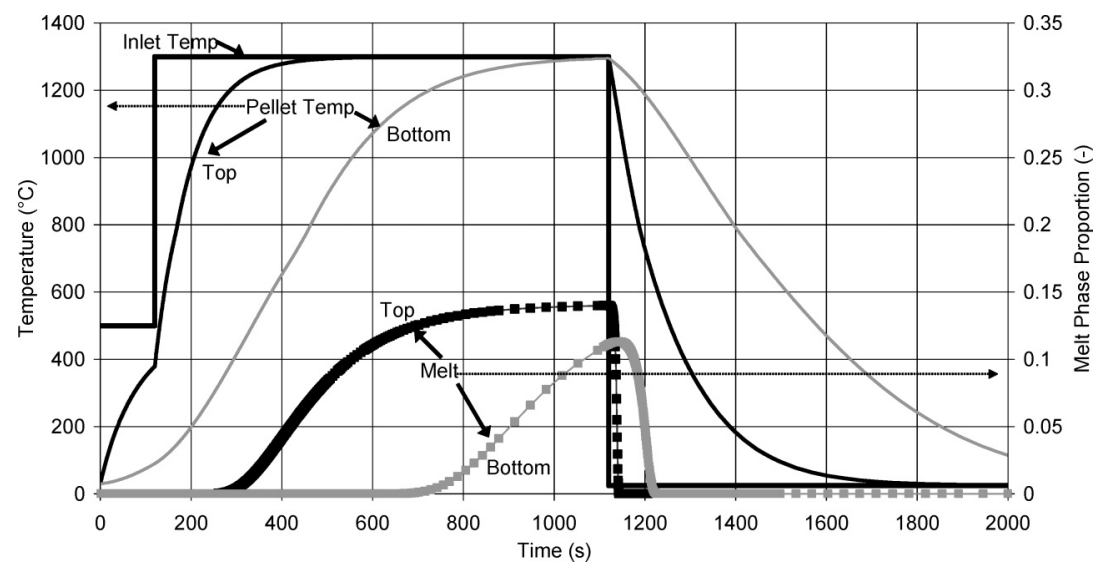

Fig. 4. Temperature profiles and melt phase formation during a mathematical simulation of pellet induration and cooling.

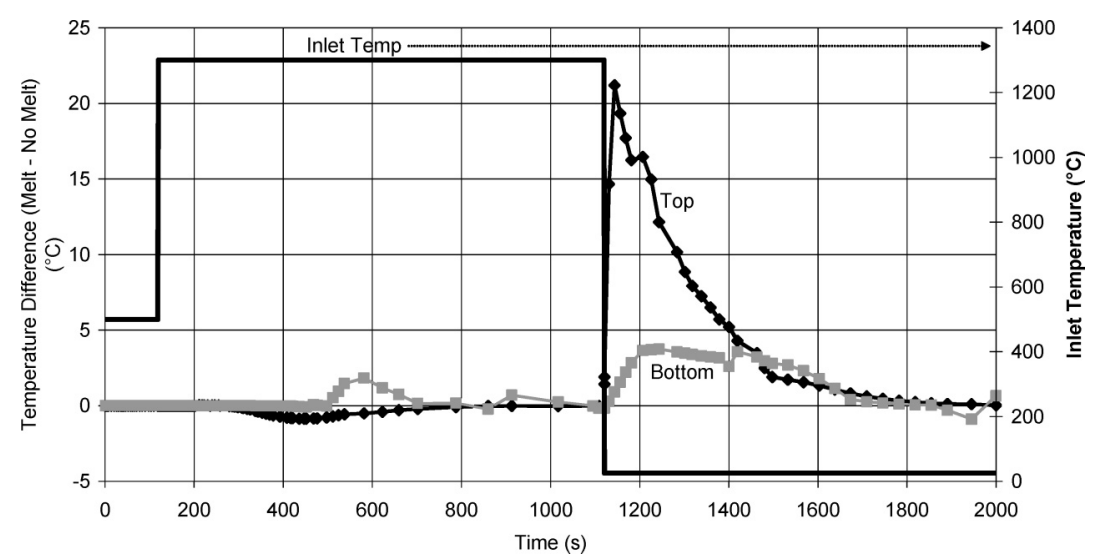

Fig. 5. Difference in temperature profile between including melt phase formation in the model (melt case) and assuming no melt is formed (no melt case).

high gangue levels. A more detailed model would require determining activity coefficients for all the component oxides.

The model used to test this reaction within a bed of pellets was a simplified version of the grate model of SIROIndur, ${ }^{6-8)}$ the pellet induration model developed by CSIRO Minerals. In this simplified model, the removal of the free moisture within the green balls was neglected but the other low temperature chemical reactions (e.g. removal of chemically bound water from goethite and calcination of carbonate fluxes) were included. Magnetite oxidation was excluded from this model as it would have overlapped the melt phase formation and made interpretation more difficult. Only a shallow bed was used $(0.17 \mathrm{~m})$ for this simulation and all gas flows were downdraught, from the top of the bed to the bottom.

\section{Results from Model}

The inlet gas temperature profile and the temperature profile through the bed of pellets can be seen in Fig. 4 along with the proportion of melt phase formation as a function of time. The profile was chosen to display an extreme case of heating and cooling of the pellets to highlight any differences. The general parameters used in the model, which was expressed in pot grate form, and a more detailed description can be found in Thurlby. ${ }^{6-8)}$

Figure 4 shows that as the melt phase formation only oc- curred gradually over time, the release of the latent heat is spread out and there are no obvious spikes in the pellet temperature profile. This is consistent with observed temperature profiles from pot grate tests for pellets produced from hematite ores. It also suggests that the absorption of latent heat from the formation of the melt phase was unimportant to the pellet temperature profile. Even during cooling, the maximum amount of heat being released by the freezing of the melt phase $(6.6 \mathrm{~kW} / \mathrm{kg})$ was three orders of magnitude smaller than the rate of heat transfer from the pellets to the gas $\left(3.3 \times 10^{3} \mathrm{~kW} / \mathrm{kg}\right)$ at the same time at top of the bed.

Figure 5 displays the difference in pellet temperature between the case where melt phase formation is included in the model and the case where it is not included in the model. Note the significant difference in the temperature profiles during cooling. It appears this difference was caused by the difference in heat capacity between the solid pellet (assumed to be hematite) and the melt. In crystalline solids, the heat capacity of the material continues to increase slowly with increasing temperature. Most liquids, however, can be assumed to have a constant heat capacity. ${ }^{22}$ This appears to have led to a significant difference of $20^{\circ} \mathrm{C}$ in the pellet temperature at the start of cooling between the "melt" and "no melt" cases. This temperature difference persists throughout the cooling process, although the difference is more significant at the top of the bed where the thermal fluxes would be greatest. The difference in terms of the overall energy balance for the induration of the pellets 
comes to about a $1-1.5 \%$ increase in energy input if the melt reaction described here was included in the model (based on a hematite ore grate-kiln plant). This difference suggests that, while there was some impact on the predicted temperature profiles when melt phase formation was included in the model, accurate assessment of the overall energy usage requires accurate information on heats of formation and fusion.

\section{Conclusions}

The modelling results suggest that the most important thermodynamic parameters to be determined are the specific heat values for solid SFC and derivative compounds like SFCA, and especially the liquid phase of iron ore pellets during firing. Experiments for the solid phase would determine if there are any magnetic effects in the heat capacity, a common occurrence in many oxides with a high proportion of iron, although not in pure calcium ferrites. ${ }^{28)}$ Experiments to determine the thermodynamic properties of SFC have been planned and will be the subject of a subsequent paper.

The modelling results also suggest that the approximation used in the current version of SIRO-Indur, ${ }^{6-8)}$ which reduces the rate of increase in heat capacity with temperature above $1000^{\circ} \mathrm{C}$ for the hematite component of the pellets, would be acceptable for determining pellet temperature profiles provided it is tailored to the chemical composition of the pellets. More detailed model predictions, including energy balance determination and phase composition of the product pellets (with a view to estimating pellet physical and metallurgical properties) would require more detailed modelling of the reactions and phase changes involved.

To improve understanding of the kinetics of melt formation and precipitation of melt phases during cooling, experimental work using a rapid heating furnace with a nitrogen quenching and rapid cooling capability will be undertaken. Quenching the reaction at various time and temperature profile combinations should be able to confirm the kinetic model assumed for melting in this investigation. The validity of these experiments would be backed up by nitrogen quenching experiments using the CSIRO Minerals pot grate induration facility. Observation of and phase abundance in the quenched pellets would be performed using optical measurement of mineralogy and texture supported by electron microprobe analysis of the composition ranges of the mineral phases.

\section{Acknowledgements}

Dr John Clout and Dr Mark Pownceby are both acknowledged for their assistance in explaining the formation mechanisms of the liquid phase in iron ore pellet induration and for reviewing earlier drafts of this paper.

\section{REFERENCES}

1) N. A. Hasenak, P. A. M. Lebelle and J. J. Kooy: Mathematical Models in Iron and Steelmaking, The Metals Society, London, (1975), 6 .

2) J. A. Thurlby, R. J. Batterham and R. E. Turner: Int. J. Miner. Process, 6 (1979), 43.

3) M. Cross: Applications of Mathematical and Physical Models in the Iron and Steel Industry, ISS-AIME, Warrendale, PA, (1982), 101.

4) T. E. Norgate, J. A. Thurlby, R. J. Batterham and B. C. Povey: 4th Int. Symp. Agglomeration, ISS, Warrendale, PA, (1985) 721.

5) R. W. Young, M. Cross and R. D. Gibson: Ironmaking Steelmaking, 6 (1979), 1.

6) J. A. Thurlby: Metall. Trans. B, 19B (1988), 103.

7) J. A. Thurlby: Metall. Trans. B, 19B (1988), 113.

8) J. A. Thurlby: Metall. Trans. B, 19B (1988), 123.

9) S. Caron, G. Ouellet, D. Roy and G. Paquet: 49th Ironmaking Conf., ISS, Warrendale, PA, (2000), 439.

10) J. R. Wynnyckyj and R. J. Batterham: 4th Int. Symp. on Agglomeration, ISS, Warrendale, PA, (1985), 957.

11) M. I. Pownceby, J. M. F. Clout, M. J. Fisher-White: Trans. Inst. Min. Metall. C, 107 (1998), C1.

12) M. J. Cumming and J. A. Thurlby: Ironmaking Steelmaking, 17 (1990), 245

13) J. Mitterlehner, G. Loeffler, F. Winter, H. Hofbauer, H. Schmid, E. Zwittag, T. H. Buergler, O. Pammer and H. Stiasny: ISIJ Int., 44 (2004), 11.

14) M. I. Pownceby, J. M. F. Clout and M.J. Fisher-White: Trans. Inst. Min. Metall. C, 107C (1998), C1.

15) M. I. Pownceby and T. R. C. Patrick: Eur. J. Mineral., 12 (2000), 455.

16) W. G. Mumme, J. M. F. Clout and R. W. Gable: N. Jb. Miner. Abh., 173C (1998), 93.

17) L. Yang, C. E. Loo and J. Ostwald: Trans. Inst. Min. Metall. C, 99C (1990), C80.

18) N. V. Y. Scarlett, M. I. Pownceby, I. C. Madsen and A. N. Christensen: Metall. Mater. Trans. B, 35B (2004), 929.

19) J. D. G. Hamilton: Trans. Inst. Min. Metall. C, 85C (1976), C30.

20) J. M. F. Clout and J. R. Manuel: Powder Tech., 130 (2003), 393.

21) J. F. Wilhelmy: COREM Pelletising Symp., COREM, Québec, (2003).

22) O. Kubaschewski and C. B. Alcock: Metallurgical Thermochemistry, Pergamon Press, Sydney, (1979), 179.

23) O. Kubaschewski, C. B. Alcock and P. J. Spencer: Materials Thermochemistry, Pergamon Press, New York, (1993), 163.

24) G. K. Moiseev and J. Sestak: Prog. Cryst. Growth Charact., 30 (1995), 23.

25) S. Aronson: J. Nuclear Mater, 107 (1982), 343.

26) O. Kubaschewski and H. Ünal: High Temp.-High Press., 9 (1977), 361.

27) K. K. Kelley: US Bureau of Mines Bull., 371 (1932).

28) K. R. Bonnickson: J. Am. Chem. Soc., 76 (1954), 1480.

29) R. A. Robie, B. S. Hemingway and J. R. Fisher: Thermodynamic Properties of Minerals and Related Substances at 298.15 K and $1 \mathrm{Bar}$ $\left(10^{5}\right.$ Pascals) Pressure and at Higher Temperatures, United States Government Printing Office, Washington, (1978), 251.

30) I. Barin: Thermochemical Data of Pure Substances, VCH, New York, (1989), 317.

31) W. M. Latimer: J. Am. Chem. Soc., 73, (1953), 1480.

32) K. T. Jacob, N. Dasgupta and Y. Waseda: Z. Metallk., 90 (1999), No. 7, 486 .

33) S. Forsberg, P. Wikström and E Rosén: Metall. Mater. Trans. B, 33B, (2002), 385. 